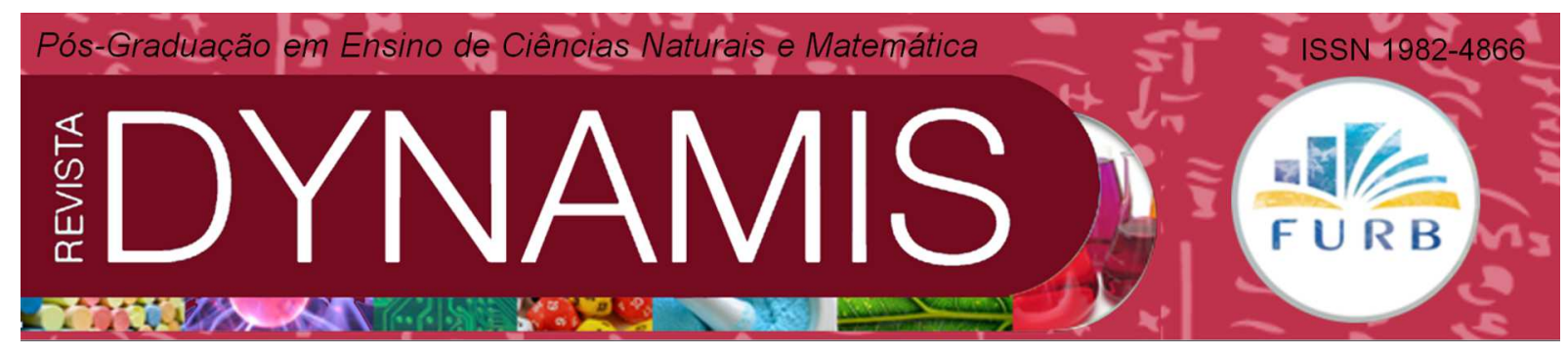

\title{
UM RELATO DE VIVÊNCIA DA UTILIZAÇÃO DO SOFTWARE MODELLUS E DE MAPAS CONCEITUAIS NO ENSINO DE FÍSICA
}

An account of living the using the software Modellus and conceptual maps

in Physics Teaching

Humberto da Silva Oliveira

Morgana Ligia de Farias Freire

Filomena Maria Gonçalves da S. Cordeiro Moita 


\title{
Resumo
}

Este texto tem como objetivo relatar uma vivência em sala de aula, feita na tentativa de aplicar a Teoria da Aprendizagem significativa de Ausubel, utilizando o software Modellus, em conjunto com a utilização de mapas conceituais no estudo do movimento dos projéteis. Para isso, a vivência foi realizada com uma turma do $1^{\circ}$ ano do Ensino Médio, seguindo-se as orientações do $\mathrm{PCN}+$ para o ensino de Física. Como instrumentos de avaliação da vivência foram utilizados entrevista e observação. Os resultados revelaram que a abordagem utilizada no processo de ensino e aprendizagem, para a apresentação do conteúdo, possibilitou uma participação mais ativa dos alunos, que demonstraram interesse e curiosidade em manusear o computador para explorar os conceitos estudados em sala de aula.

Palavras-chave: Física. Modellus. Mapas conceituais. Aprendizagem significativa.

\begin{abstract}
This text aims to present an experience in the classroom, made in an attempt to implement the Meaningful Learning Theory of Ausubel, by using the software Modellus, in conjunction with using of conceptual maps in the study of the motion of projectiles. For this, the living has been conducted with a class of 1st year of High School, following the orientations of the $\mathrm{PCN}+$ for the teaching of physics. As of living instruments of evaluation were used interview and observation. The results showed that the approach used in the process of teaching and learning, for the presentation of content, permitted the more active participation of the students who demonstrated interest and curiosity in handling the computer to explore the concepts studied in class.
\end{abstract}

Keywords: Physics. Modellus. Concept maps. Meaningful learning. 


\section{INTRODUÇÃO}

No ensino médio, a Física é considerada pela maioria dos alunos como uma das disciplinas mais difíceis. Essa dificuldade tem como origem diversos motivos, tais como: a não percepção dos conceitos físicos, no cotidiano, ou concepções equivocadas dos fenômenos físicos, que são desenvolvidas espontaneamente e trazidas para a sala de aula, a valorização em demasia de expressões matemáticas em relação aos conceitos físicos (ZYLBERSZTAJN, 1983), entre outros motivos citados por Menegotto e Rocha Filho (2008). Além disso, tem-se que a aplicação de ferramentas educacionais para facilitar o processo de ensino e aprendizagem é pouco explorada.

Perante as dificuldades encontradas no ensino da Física, questionamos se é possível aproveitar os avanços tecnológicos que permeiam o cotidiano da sociedade e aplicar essas tecnologias em sala de aula. Por isso, são necessários estudos sobre diferentes metodologias de ensino-aprendizagem, e uma delas é o estudo das tecnologias aplicadas ao ensino, que escolhemos para ser empregada e avaliada no ensino de Física, com o intuito de verificar se essa metodologia facilita o ensino, se o torna mais atraente, se estimula a curiosidade dos alunos e se promove uma aprendizagem mais significativa, tornando o trabalho do professor mais eficiente.

Para realizar este estudo, optamos pela utilização do computador e de um software de simlução e modelação, chamado Modellus, em conjunto com a aplicação de mapas conceituais para apresentar o conteúdo e estudar os movimentos de projéteis, numa intervenção didática, na tentativa de propiciar uma aprendizagem significativa, partindo dos conhecimentos prévios dos alunos, até a assimilação dos novos conhecimentos.

\section{APRENDIZAGEM SIGNIFICATIVA}

A aprendizagem significativa é um conceito enfatizado por David Ausubel desde a década de 1960, que a concebe como um processo por meio do qual uma nova informação se relaciona com um aspecto relevante da estrutura de conhecimento do indivíduo. Nesse processo, a nova informação interage com uma estrutura de conhecimento específica, que Ausubel, Novak e Hanesian (1980) definem como o conceito subsunçor ou, simplesmente, subsunçor (subsumer), existente na estrutura cognitiva do indivíduo. A aprendizagem significativa ocorre, quando a nova informação se ancora em subsunçores relevantes preexistentes na estrutura cognitiva de quem aprende (MOREIRA; MASINI, 2006).

Os subsunçores são os conhecimentos prévios existentes na estrutura cognitiva do aprendente. "É um conceito, uma ideia, uma proposição já existente na estrutura cognitiva, capaz de servir de 'ancoradouro' a uma nova informação de modo que esta adquira, assim, significado para o indivíduo" (MOREIRA, 2009, p.8). Quando a nova informação consegue ser assimilada na estrutura cognitiva do aprendiz e se ancora nos subsunçores, de tal forma que os tornam mais abrangentes, pode-se afirmar que a aprendizagem foi significativa.

Ressalte-se, no entanto, que a aprendizagem significativa só será efetivamente realizada, com algumas condições, "uma delas é que o material seja potencialmente significativo. A outra é que o aprendiz manifeste uma disposição para relacionar, de maneira substantiva e 
não-arbitrária, o novo material, potencialmente significativo à sua estrutura cognitiva" (MOREIRA, 2009, p.12-13). Portanto, mesmo que o material a ser aprendido seja potencialmente significativo, se a intenção do aprendiz for memorizá-lo de forma arbitrária e literária, o resultado será uma aprendizagem não significativa, chamada por Ausubel et al. (1980) de aprendizagem automática ou mecânica. Da mesma forma se o material não for potencialmente significativo, a aprendizagem não será significativa. Entende-se por material de ensino potencialmente significativo, aquele que pode ser incorporado, de forma não-literal e não-arbitrária, na estrutura cognitiva do aprendiz.

Mesmo que as condições anteriores sejam satisfeitas, ainda existe o risco do aprendiz não realizar uma aprendizagem significativa, pois, se a sua estrutura cognitiva não possuir ideias (conceitos) relevantes que sirvam de ancoradouros para as novas ideias (conceitos) apresentadas, ele não terá condições de aprender de maneira significativa. Para resolver essa dificuldade Ausubel (2003) utiliza um mecanismo pedagógico, chamado de organizador avançado, que desempenha um papel de mediador (ponte), "estabelecendo uma ligação entre aquilo que o aprendiz já sabe e aquilo que precisa saber, caso necessite de aprender novos materiais de forma mais ativa e expedita" (AUSUBEL, 2003, p. 11).

Os organizadores avançados são uma estratégia de ensino, que tem a função de preencher a lacuna existente na estrutura cognitiva do aprendiz para aprender os novos conceitos. Os organizadores avançados podem assumir diferentes formas, uma delas é a forma de mapa conceitual, Novak (2000, p. 71) descobriu que "os mapas conceituais são ferramentas eficazes para indagar o que o formando já sabe, incluindo estruturas de conhecimento defeituosas ou ideias erradas e, também, para organizar o assunto do novo material a ser ensinado."

\subsection{MAPAS CONCEITUAIS}

Seguindo o conceito da Teoria da Aprendizagem de Ausubel, foram realizados diversos estudos, porém, um dos mais produtivos e divulgados nos meios acadêmicos foi o produzido por Joseph Novak e seus colaboradores, que conseguiram idealizar uma estratégia de aplicação da referida teoria.

A ferramenta educacional, idealizada por Joseph Novak e colaboradores, é a construção de mapas conceituais, que é uma forma de verificar os significados dos materiais aplicados em sala de aula e colocar no papel, de maneira simplificada, as conexões existentes entre os conceitos estudados. "Um mapa conceitual é um recurso esquemático que serve para representar um conjunto de significados conceituais incluídos numa estrutura de proposições" (NOVAK, 1996, p. 31).

A utilização dos mapas conceituais, nos processos de ensino e aprendizagem de conteúdos de Física, possibilita uma visualização hierárquica dos conceitos e de suas conexões, pois os conteúdos de Física têm conceitos mais inclusivos, que podem ser utilizados como subsunçores para se adquirirem novos conhecimentos.

\subsection{SOFTWARE MODELLUS}

Juntamente com o princípio ausubeliano da aprendizagem significativa e com os mapas conceituais de Novak, podemos utilizar softwares educacionais que resultem em animações interativas. A utilização de mapas conceituais com animações interativas funciona como um suporte para o aprendizado autônomo (TAVARES, 2005). 
Dentre os vários softwares educativos, foi utilizado o software Modellus, desenvolvido por Vitor Duarte Teodoro, com a colaboração de João Paulo Duque Vieira e Felipe Clérigo, na Faculdade de Ciências e Tecnologia da Universidade de Nova Lisboa em Portugal (TEODORO, 2002). Esse software é um ambiente computacional que simula fenômenos físicos, para que os professores e os alunos criem e explorem os modelos, possam observar, de forma dinâmica, o fenômeno e alterar os parâmetros e as condições iniciais. Teodoro descreve o Modellus como uma ferramenta educacional que:

\begin{abstract}
[...]permite ao utilizador fazer e refazer representações, explorando-as sobre as mais diversas perspectivas. Deste modo, facilita a familiarização com essas representações, criando de certo modo uma intimidade entre aprendiz e representação, intimidade essa que muito dificilmente resulta da simples observação ocasional de equações e representações feitas pelo professor ou apresentadas nos livros. (TEODORO, 2002, p. 21).
\end{abstract}

Com esse software, também é possível trabalhar a linguagem própria da Física, empregando conceitos e terminologias bem definidos, além de suas formas de expressão, com tabelas, gráficos ou relações matemáticas, como está preconizado nas orientações educacionais complementares aos Parâmetros Curriculares da Física (MEC, 2002).

\title{
3 MATERIAL E MÉTODOS
}

Aplicamos a Teoria da Aprendizagem Significativa, no sentido de verificar os conhecimentos prévios dos alunos referentes ao estudo da cinemática de um ponto material, para isto, empregamos um questionário para avaliar o nível de conhecimento inicial dos alunos, após identificação dos subsunçores necessários, destacando-se os conceitos de posição, velocidade e aceleração, utilizamos simulações criadas no software Modellus, em conjunto com mapas conceituais, em uma turma do $1^{\circ}$ ano do ensino médio noturno, 15 alunos, de uma escola pública da rede estadual da Paraíba, no município de João Pessoa.

Foi entregue um texto para os alunos lerem em grupo e discutirem entre si os conceitos relacionados ao conteúdo estudado em sala de aula. Esse texto foi utilizado como organizador avançado para introduzir o conteúdo partindo de situações esportivas.

\section{Texto ${ }^{1}$}

"Quando um atleta arremessa um dardo, um peso, um disco ou mesmo seu próprio corpo (saltos em altura ou em distância, conforme a Figura 1), esses objetos descrevem praticamente trajetórias parabólicas, características do movimento de um projétil. $O$ alcance que o atleta obtém em qualquer um desses lançamentos, além de depender dos valores de $V_{0}$ e de $\theta$, é inversamente proporcional ao valor da aceleração da gravidade. Portanto, como era de esperar, em um local onde o valor de g é mais elevado, o alcance é menor e viceversa.

\section{Figura 1 - Salto em distância².}

\footnotetext{
${ }^{1}$ LUZ, A. M. R. Curso de Física. São Paulo: Scipione, 2005.

${ }^{2}$ Imagem retirada do site www.zaroio.com.br.
} 


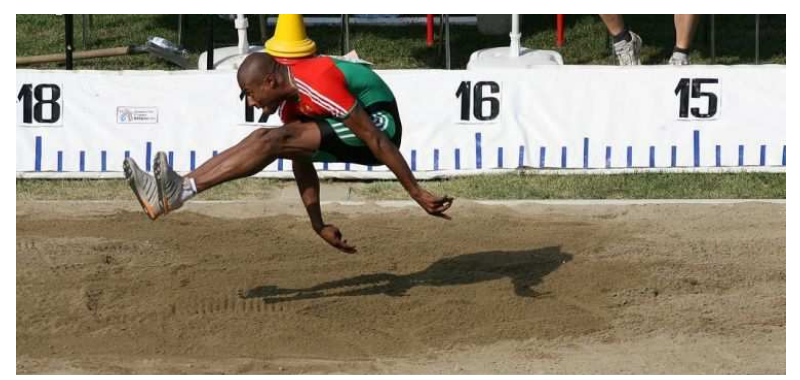

Fonte: Zaroio

Por esta razão, um atleta que arremessar um dardo, por exemplo, em uma cidade onde o valor de g é relativamente pequeno (como na Cidade do México), será beneficiado. Cálculos cuidadosos mostram que as variações de $\mathrm{g}$ de um local para outro podem acarretar diferenças de até $3 \mathrm{~cm}$ no alcance de um arremesso de peso. Uma vez que as medições em competições esportivas internacionais são, atualmente, realizadas com grande precisão, uma diferença como a citada pode levar um atleta a receber, injustamente, um título de recordista mundial. Embora as correções necessárias para evitar esse problema possam ser feitas com facilidade, ao que tudo indica, elas não costumam ser levadas em conta pelas autoridades competentes.

Após esse trabalho, em uma hora-aula, foi apresentado e explanado um mapa conceitual sobre o lançamento oblíquo, conforme apresentado na Figura 2. Esse mapa conceitual serviu de organizador avançado, pois utilizamos para organizar e apresentar os conceitos envolvidos no lançamento oblíquo relacionando com conceitos mais abrangentes com conceitos estudados anteriormente, tais como os conceitos de velocidade, aceleração, movimento, trajetória, entre outros.

Figura 2- Mapa conceitual do Lançamento Oblíquo

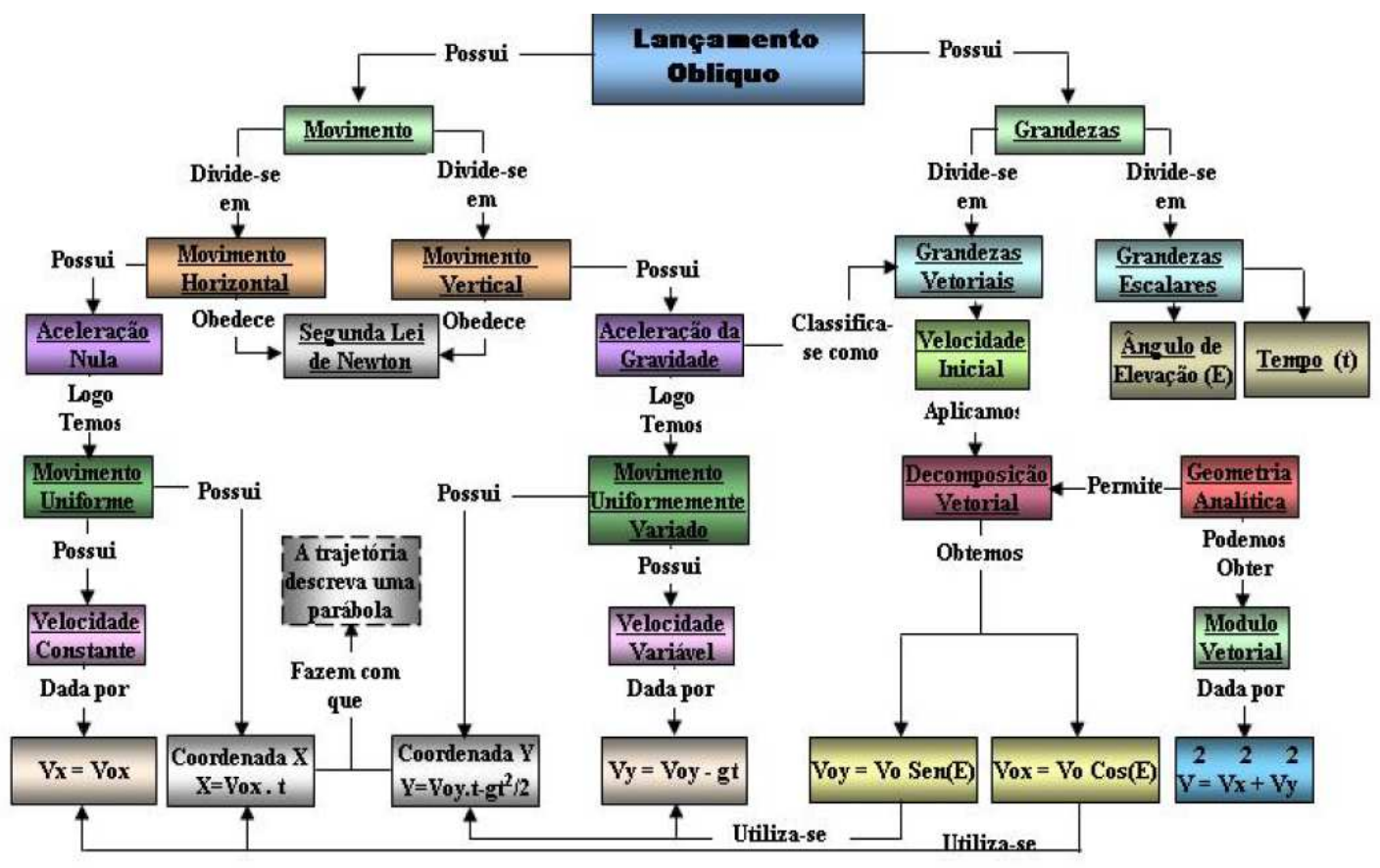

Fonte: Silva (2006) 
Após o estudo do mapa conceitual em sala de aula, foi apresentado o software Modellus, cuja versão utilizada foi a 4.01, que pode ser encontrada na internet ${ }^{3}$. As simulações foram realizadas no laboratório de informática, com o tempo total de quatro horas-aula. Nessa etapa, os alunos tiveram a oportunidade de visualizar o comportamento dinâmico dos movimentos, interagiram com o modelo e modificaram os valores iniciais da velocidade, da aceleração gravitacional e do ângulo de lançamento.

Nas simulações, perceberam (conforme ilustrado na Figura 3) que, em cada instante, a velocidade vetorial v é tangente à trajetória; em qualquer instante, a componente horizontal da velocidade $\left(\mathrm{v}_{\mathrm{x}}\right)$ é constante; a componente vertical da velocidade $\left(\mathrm{v}_{\mathrm{y}}\right)$ decresce na subida, torna-se zero, no ponto mais alto da trajetória e passa a crescer negativamente; as coordenadas do projétil, em qualquer instante, correspondem exatamente à abscissa da projeção horizontal do projétil e à ordenada da sua projeção vertical. Os alunos constataram que, de fato, o movimento do projétil na trajetória parabólica pode ser decomposto num movimento uniforme, na horizontal, e num movimento uniformemente variado na vertical; nos gráficos da velocidade, podem-se verificar a constância da projeção horizontal da velocidade, a variação da projeção vertical da velocidade, assim como o módulo da velocidade do projétil em qualquer instante; o módulo da velocidade do projétil, no momento do impacto, é igual ao módulo da velocidade de seu lançamento.

Figura 3 - Gráficos do movimento de projéteis

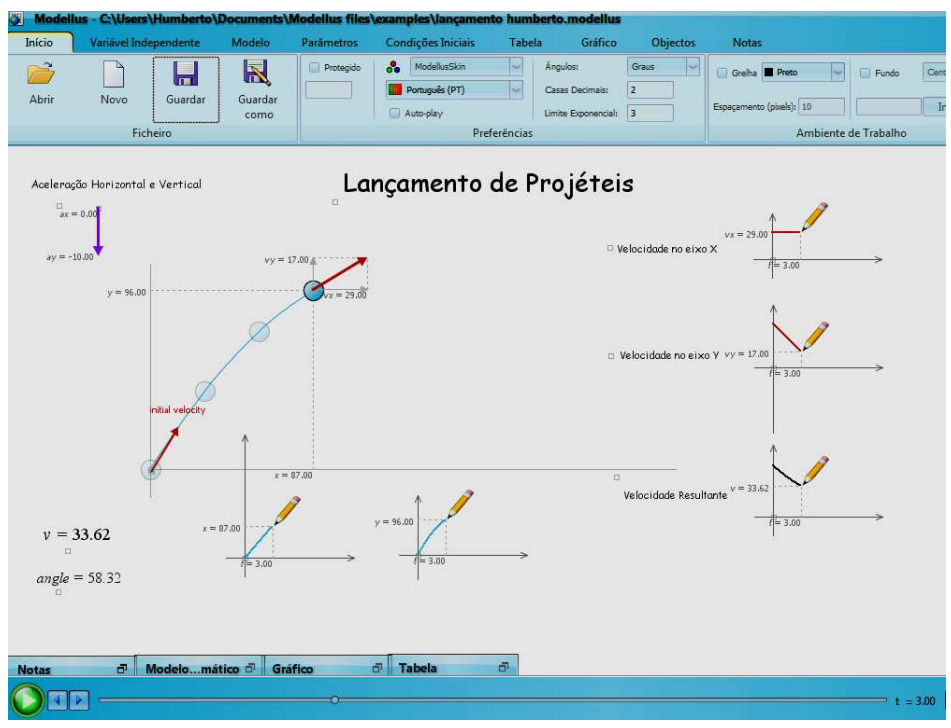

Fonte: Reprodução da simulação desenvolvida pelo autor

Na simulação da situação apresentada na Figura 4, os alunos verificaram: a altura atingida pelo projétil e o alcance horizontal em função da velocidade inicial e do ângulo de lançamento; para uma determinada velocidade inicial de lançamento, qual o ângulo em que ocorre o máximo alcance horizontal e para uma determinada velocidade inicial de lançamento, que um mesmo alcance horizontal é obtido para dois ângulos complementares entre si.

\footnotetext{
${ }^{3}$ http://modellus.fct.unl.pt/
} 


\section{Figura 4 - Simulação do movimento de projéteis}

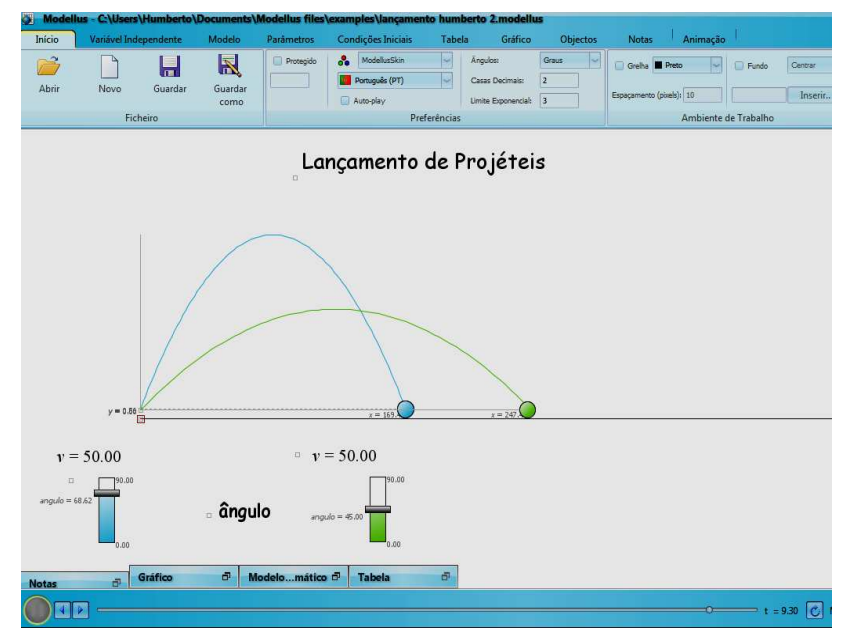

Fonte: Reprodução da simulação desenvolvida pelo autor

\section{RESULTADOS E DISCUSSÃO}

$\mathrm{Na}$ avaliação da intervenção didática, foram realizadas entrevistas em grupo, do tipo semiestruturada, no decorrer das aulas com toda a turma, acontecendo em diversos momentos: antes, durante e depois da intervenção didática. As perguntas foram as seguintes:

1. Você tem dificuldades de entender os conceitos de Física que são dados na sala de aula?

2. Você acha que o uso de simulações computacionais facilita a aprendizagem dos conteúdos de Física?

3. Você já utilizou o computador e a internet para realizar pesquisas e simulações de Física?

Além das entrevistas, fizemos o uso da observação dos momentos da intervenção, sempre acompanhando de perto todas as fases, com o objetivo de verificar a participação e envolvimento dos alunos, bem como a evolução dos mesmos no manuseio do software e da aprendizagem dos conteúdos.

Iremos retratar um pouco do que observamos no decorrer da intervenção e da aplicação da entrevista em grupo.

A primeira pergunta foi feita na primeira aula sobre os movimentos de projéteis. Percebemos que a maioria dos alunos tem muitas dificuldades de aprender Física. Muitos disseram que não veem aplicação no dia-a-dia, que tem muitas fórmulas, que acham a aula monótona.

Sobre a segunda pergunta, feita durante as aulas na sala de informática, quando os alunos apresentavam as animações desenvolvidas no Modellus, a opinião foi quase unânime em afirmar que, visualizando as animações e alterando os dados - a velocidade de lançamento, o ângulo inicial e a gravidade - fica mais fácil entender os conteúdos, sem se preocupar muito com os cálculos, pois o computador é que faz as contas. Pelos relatos dos alunos, podemos perceber que as simulações criadas no Modellus facilitaram a compreensão dos conceitos, interpretação gráfica e levantamento de hipóteses.

Abaixo temos alguns exemplos de respostas dos alunos:

Aluno 1 - "Aqui tá melhor do que na sala de aula, agente aqui aprende mais." 


\section{Aluno 2 - “Aqui agente vai testando pra ver se tá aprendendo ou não.”}

Aluno 3 - "Eu não sabia por que, antes disso, agora eu sei mais ou menos, porque eu sou horrível em matemática e física."

Estes relatos nos mostram que a aula na sala de informática com a utilização do software Modellus serviu de motivação e foi um elemento que possibilitou uma aprendizagem diferente ao da sala de aula, pois os alunos podiam fazer e refazer as simulações alterando as grandezas físicas e verificando de imediato o que acontecia, mesmo os alunos que se denominavam "horrível em matemática e física" admitiam que estavam aprendendo com o uso do software, confirmando as evidências de outras pesquisas, como a de Tavares (2005).

$\mathrm{Na}$ terceira pergunta, eles responderam que "navegam" na internet, mas não procuram pesquisar conteúdos relacionados ao estudo em sala de aula, especificamente o de Física, por isso muitos não conheciam a possibilidade de encontrar simulações de Física na internet, porquanto, na maior parte do tempo em que estão na internet, conectam-se em redes sociais.

Depois da intervenção didática, observamos que, quando os alunos tiveram a oportunidade de manusear o computador para aprender Física, com o software Modellus, perceberam a importância do uso de simulações dessa disciplina e afirmaram que as aulas ministradas na sala de informática foram mais dinâmicas, e a aprendizagem foi mais fácil.

\section{CONSIDERAÇÕES FINAIS}

Essa experiência vivenciada da aplicação do software Modellus e dos mapas conceituais no processo de ensino e aprendizagem, em uma das turmas do $1^{\circ}$ ano do ensino médio, foi gratificante, pois, ao comparar o resultado obtido desta turma, em relação a situações anteriores em que essa metodologia não foi empregada, verificamos que os resultados da aprendizagem foram superiores, tendo em vista a melhora do rendimento comprovado na avaliação aplicada após os estudos. Mas a principal constatação foi o interesse e participação dos alunos durante as aulas, pois antes não existia, indicando que a atividade programada com o software Modellus na sala de informática motivou os estudantes em sua aprendizagem.

As simulações dos modelos físicos trabalhados em sala de aula, utilizando o software Modellus, serviram para visualizar o movimento dos projéteis em função do tempo, o que favoreceu para que houvesse uma interação entre os alunos e os modelos, que puderam ser modificados e testados. Isso levantou conjecturas que promoveram uma discussão em sala de aula e os testes das hipóteses, como ficou destacado no relato do Aluno 2.

Com a participação ativa em sala de aula, os alunos tiveram a oportunidade de levantar questionamentos sobre as diversas situações em que se evidencia o movimento de projéteis e de associar os conceitos teóricos a situações práticas que já conheciam, como as atividades esportivas, vistas no texto. $\mathrm{O}$ uso do mapa conceitual serviu de organizador avançado, para introdução do conteúdo e para relacionar os conceitos novos com conceitos anteriores, tais como os conceitos de velocidade e aceleração.

Portanto, foi possível observar que houve um avanço bastante significativo na melhoria do processo de ensino e de aprendizagem de Física nessa turma. A mediação pelos mapas conceituais e a aplicação do uso das simulações fizeram com que os alunos passassem a compreender bem mais o conteúdo abordado e até procurassem novas simulações de outros conteúdos de Física. 


\section{REFERÊNCIAS}

AUSUBEL, D. P. Aquisição e retenção de conhecimentos: uma perspectiva cognitiva. Lisboa: Plátano Edições Técnicas. 2003.

AUSUBEL, D. P.; Novak, J. D.; Hanesian, H. Psicologia Educacional. 2. ed. Rio de Janeiro: Interamericana, 1980.

MEC, Secretaria de Educação Média e Tecnológica. PCN+ Ensino Médio: Orientações Educacionais Complementares aos Parâmetros Curriculares Nacionais. Ciências da Natureza, Matemática e suas Tecnologias. Brasília: MEC, SEMTEC, 2002.

MENEGOTTO, J. C.; ROCHA, J. B., F $F^{o}$ Atitudes de estudantes do ensino médio em relação à disciplina de Física. Revista Electrónica de Enseñanza de las Ciencias v. 7 n.2, 2008. Disponível: http://www.saum.uvigo.es/reec/volumenes/volumen7/ART2_Vol7_N2.pdf.

MOREIRA, M. A.; MASINI, E. F. S. Aprendizagem Significativa: a Teoria de David Ausubel. 2.ed. São Paulo: Centauro, 2006.

MOREIRA, M.A. Subsídios teóricos para o professor pesquisador em ensino de Ciências: A Teoria da Aprendizagem Significativa. Porto Alegre, Ed. do Autor, 2009.

NOVAK, J. D. Aprender, criar e utilizar o conhecimento: Mapas conceituais como ferramentas de facilitação nas escolas e empresas. Lisboa: Plátano Edições Técnicas. 2000.

NOVAK, J. D.; Gowin, D. B. Aprender a aprender. Lisboa: Editora Plátano, 1996.

SILVA, L. F. Associando realidade virtual não imersiva e ferramentas cognitivas para o ensino de Física. 2006. Dissertação (Mestrado em Ciência da Computação). Universidade Federal de Uberlândia, Minas Gerais. Disponível: http://www.dominiopublico.gov.br /download /texto/cp008751.pdf. Acesso em: 20 abr. 2014.

TAVARES, R. Animações interativas e mapas conceituais. Simpósio Nacional de Ensino de Física, XVI, Rio de Janeiro, 2005. Disponível: http://www.fisica.ufpb.br / romero/objetosaprendizagem/Rived/02aProjeteisMovimento/site/animacoesemapas.pdf.

Acesso em: 20 abr. 2014

TEODORO, V. D. Learning Physics with Mathematical Modelling. 2002. Tese de PhD (Doutorado em Ciências e Tecnologia). Universidade Nova de Lisboa, Lisboa. Disponível: http://run.unl.pt/bitstream/10362/407/1/teodoro_2002.pdf. Acesso em: 20 abr. 2014

ZYLBERSZTAJN, A. Concepções espontâneas em Física: exemplos em dinâmica e implicações para o ensino. Revista de Ensino de Física. v.5, n.2, p.3-16, dezembro de 1983. Disponível: http://www.sbfisica.org.br/rbef/pdf/vol05a09.pdf. Acesso em: 20 abr. 2014 